\title{
Finger clubbing and altered carbon monoxide transfer capacity in cannabis smokers
}

\section{To the Editors:}

The harmful effects of cannabis smoking on the lung include: an increased risk of airway obstruction [1] and, presumably, of lung cancer; large cystic and bullous changes [2]; pneumothorax; and pneumomediastinum. Here we report on two patients with finger clubbing and hypoxaemia, probably related to long-term smoking of cannabis, in the absence of any overt disease.

The first patient, a 26-yr-old male, presented with chronic dyspnoea on exertion. He had 10 pack-yrs of tobacco smoking and had smoked 15 cannabis cigarettes per day for 10 yrs. Examination was unremarkable except for marked digital clubbing of the hands and feet. Pulmonary function tests (PFTs) were within normal limits (table 1), except for decreased carbon monoxide (CO) lung transfer capacity and hypoxaemia at exercise. A computed tomography (CT) scan of the chest was normal, and alveolar-arterial oxygen tension difference $\left(\mathrm{PA}-\mathrm{a}, \mathrm{O}_{2}\right)$, while breathing $100 \%$ oxygen was normal.

The patient quit tobacco smoking and persistently reduced cannabis use to one cannabis cigarette per month. One year later, dyspnoea had resolved and finger clubbing had almost disappeared. Spirometry was normal. The transfer factor and the transfer coefficient of the lung for $\mathrm{CO}(\mathrm{KCO})$ had both increased to 73 and $67 \%$ of the predicted, respectively. Arterial oxygen tension at rest was $9.5 \mathrm{kPa}$ (supine) and $11.2 \mathrm{kPa}$ (upright), and $10.2 \mathrm{kPa}$ at exercise $(10 \mathrm{~min}$ at $50 \mathrm{~W}) ; \mathrm{PA}-\mathrm{a}, \mathrm{O}_{2}$ was elevated in the supine

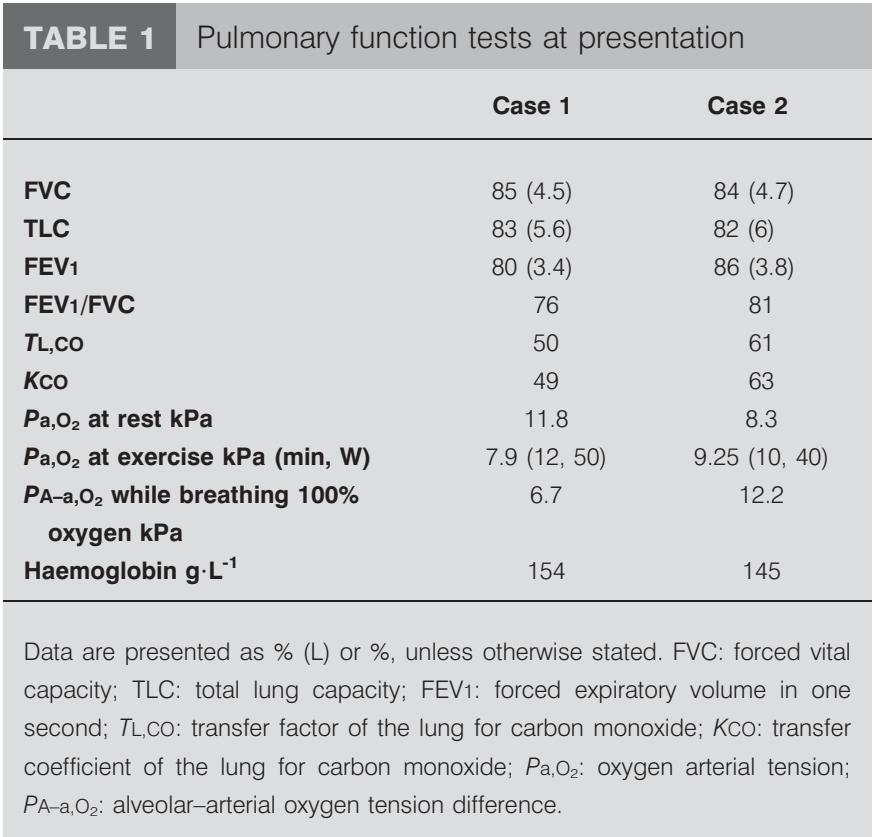

position $(27 \mathrm{kPa})$ and normal while standing (14 kPa). Contrast echocardiography was normal in supine and upright positions.

The second patient, a 27-yr-old male, was referred for marked finger clubbing and chronic dyspnoea at exercise. He had smoked 20 cigarettes of tobacco and $\sim 10$ cigarettes of cannabis per day for 8 yrs. PFTs demonstrated normal volumes but there was decreased CO transfer and hypoxaemia at rest. A CT scan of the chest showed mild paraseptal emphysema.

18-F-fluoro-2-deoxyglucose-positron emission tomography, radionuclide lung scanning, echocardiography and routine blood tests were normal in both patients.

Finger clubbing in our patients could not be related to any known cause or family history despite thorough evaluation, and was eventually considered to be related to heavy cannabis use, with 150 and 80 cannabis cigarette-yrs, respectively (i.e. daily number of cannabis cigarettes $\times$ number of yrs smoked). The previously unreported regression of the finger clubbing upon reduction of cannabis smoking confirmed its responsibility (although the patient also quit tobacco smoking), as previously suspected [3]. In addition, both cases presented with severe hypoxaemia at exercise and alteration of CO transfer capacity, despite the lack of significant emphysematous changes on chest imaging and the absence of any obstructive defect at spirometry. These observations contrast with the reported lack of effect of cannabis on KCO [1].

The pathophysiology of cannabis-induced finger clubbing remains speculative. We hypothesise that the drug may increase the expression of vascular endothelial growth factor- $\alpha$ or of its receptor [4]. Cannabis-induced alteration of carbon monoxide transfer may be related to vascular changes and/or infiltration by pigmented macrophages of the alveolar interstitium and capillaries of the lung, as shown by autopsy analysis of cannabis smokers (also showing bronchiolar inflammation) [5].

\section{A. Schuller*, V. Cottin*, A. Hot ${ }^{\#}$ and J-F. Cordier* \\ *Dept of Respiratory Diseases, Reference Center for Orphan Lung Disorders, Louis Pradel Hospital, Hospices Civils de Lyon, Lyon I University "Dept of Internal Medicine, Edouard Herriot Hospital, Hospices Civils de Lyon, Lyon, France.}

\section{STATEMENT OF INTEREST}

None declared.

\section{REFERENCES}

1 Aldington S, Williams M, Nowitz M, et al. The effects of cannabis on pulmonary structure, function and symptoms. Thorax 2007; 62: 1058-1063. 
2 Johnson MK, Smith RP, Morrison D, et al. Large lung bullae in marijuana smokers. Thorax 2000; 55: 340-342.

3 Baris YI, Tan E, Kalyoncu F, et al. Digital clubbing in hashish addicts. Chest 1990; 98: 1545-1546.

4 Atkinson S, Fox SB. Vascular endothelial growth factor (VEGF)-A and platelet-derived growth factor (PDGF) play a central role in the pathogenesis of digital clubbing. J Pathol 2004; 203: 721-728.

5 Morris RR. Human pulmonary histopathological changes from marijuana smoking. J Forensic Sci 1985; 30: 345-349.

DOI: $10.1183 / 09031936.00150907$

\section{Environmental temperature and relative humidity influence exhaled breath condensate $\mathrm{pH}$}

\section{To the Editors:}

Exhaled breath condensate (EBC) is used to obtain information about the composition of airway surface lining fluid [1]. Acidification of EBC has been reported in different inflammatory airway diseases [2]. Interpretation of data is compromised by the fact that condensate $\mathrm{pH}$ shows day-to-day variability, even in healthy subjects [3]. Coating of condensing surfaces [4] and salivary contamination of the condensate [5] have been proposed to influence exhaled biomarker levels. It was our aim to investigate whether environmental temperature and relative humidity could influence condensate $\mathrm{pH}$ and whether they could be responsible for the observed variability.

EBC was collected from 12 healthy subjects with an R-Tube condenser (Respiratory Research Inc., Charlottesville, VA, USA) before and after the forecasted arrival of three cold, humid and two warm, dry meteorological fronts. In summer, on three occasions the room temperature and relative humidity paralleled the outside conditions; in winter, on two occasions room temperature and relative humidity were maintained at $26^{\circ} \mathrm{C}$ and between $47-52 \%$.

EBC $\mathrm{pH}$ was determined using the carbon dioxide $\left(\mathrm{CO}_{2}\right)$ standardisation method, as described previously [3]. Briefly, $\mathrm{pH}$ and $\mathrm{CO}_{2}$ were measured using a blood gas analyser (ABL 520; Radiometer, Copenhagen, Denmark) five times consecutively after 1-s $\mathrm{CO}_{2}$ load to the sample between each measurement. A $\mathrm{pH}-\mathrm{CO}_{2}$ plot was created from the results. The $\mathrm{pH}$ at $5.33 \mathrm{kPa} \mathrm{CO}$ partial pressure was calculated using the logarithmic regression equity obtained from the plot.

The arrival of forecasted meteorological fronts caused a pronounced change both in temperature and relative humidity of ambient air (table 1). In summer, when the study room conditions paralleled the weather conditions outside, EBC $\mathrm{pH}$ decreased significantly with the humid, cold fronts and inversely increased with the dry, warm front. In winter, when room conditions were controlled, EBC $\mathrm{pH}$ was not affected significantly by either the humid, cold or the dry, warm fronts. The coefficient of variation of EBC $\mathrm{pH}$ was $3.0 \pm 1.3$ under uncontrolled room conditions in summer and $1.8 \pm 0.9$ under controlled temperature and relative humidity of the room in winter $(p<0.02)$. There was no correlation between $\mathrm{pH}$ and volume of condensates.

The results have two possible readings, one clinical and the other pathophysiological. From a clinical point of view the results

\begin{tabular}{|c|c|c|c|c|c|c|}
\hline \multirow{2}{*}{$\begin{array}{l}\text { TABLE } 1 \\
\text { Season }\end{array}$} & \multicolumn{6}{|c|}{$\begin{array}{l}\text { Effect of meteorological fronts on exhaled breath } \\
\text { condensate (EBC) } \mathrm{pH}\end{array}$} \\
\hline & Front & Day & $\begin{array}{c}\text { Temp. } \\
{ }^{\circ} \mathrm{C}\end{array}$ & $\mathbf{R H}$ & EBC pH & p-value \\
\hline \multirow[t]{6}{*}{ Summer } & Humid & Before & 29 & 53 & $6.11 \pm 0.18$ & 0.008 \\
\hline & & After & 18 & 74 & $5.92 \pm 0.19$ & \\
\hline & Humid & Before & 30 & 38 & $5.96 \pm 0.20$ & 0.030 \\
\hline & & After & 23 & 53 & $5.83 \pm 0.13$ & \\
\hline & Dry & Before & 23 & 40 & $5.88 \pm 0.20$ & 0.015 \\
\hline & & After & 31 & 36 & $6.02 \pm 0.16$ & \\
\hline \multirow[t]{4}{*}{ Winter } & Humid & Before & 16 & 53 & $6.00 \pm 0.15$ & NS \\
\hline & & After & 5 & 83 & $5.97 \pm 0.16$ & \\
\hline & Dry & Before & 1 & 55 & $5.98 \pm 0.24$ & NS \\
\hline & & After & 12 & 42 & $5.95 \pm 0.14$ & \\
\hline
\end{tabular}

Temperature (temp.) and relative humidity $(\mathrm{RH})$ were registered at the time of collections. Study room temperature and $\mathrm{RH}$ paralleled the outside conditions in summer and were kept at $26^{\circ} \mathrm{C}$ and between $47-52 \%$ in winter. EBC pH values are presented as mean \pm SD. NS: nonsignificant.

suggest that controlling room temperature and relative humidity should be part of standardisation of EBC collection. From a pathophysiological point of view the results are interesting as they may contribute to the explanation of catching a common cold. It is not clear why the microbes that are present continuously in the air and on the mucous membranes cause respiratory tract infections that are more likely in cold weather. Compared with the stability of blood $\mathrm{pH}$, changes $\geqslant 0.5$ may occur in the $\mathrm{pH}$ of EBC and probably, therefore, the airway surface lining fluid. A relative important change in $\mathrm{pH}$ may result in a decrease in the ciliary beat [6] or in the activity of immune cells. The deterioration in the function of the nonspecific immune barrier may allow the viruses to invade the tissues.

It is widely accepted that meteorological factors can trigger several respiratory diseases. Asthma attacks have been related to: the rupture of pollens during thunderstorms [7]; higher concentrations of sulphur dioxide, nitric oxide and carbon monoxide in the air; and lower temperature and sunshine hours [8]. Exacerbations of chronic obstructive pulmonary disease have been demonstrated to be more frequent in cold weather [9]. 